\title{
HYPOTENSIVE DRUGS IN THE TREATMENT OF DEPRESSION
}

\author{
R.P. SNAITH \\ Stanley Royd Hospital, Wakefield
}

This paper describes a study in the field of epidemiology concerned not with psychotropic drugs but with drugs used for the treatment of hypertension. Nonetheless it illustrates the use of a self-rating technique and highlights some of the necessary precautions when such a technique is used in epidemiological work. Our experience may have some applications in the field of psychotropic drug evaluation. The research is an instance of collaboration between a psychiatrist and a general practitioner, myself and Dr Malcolm McCoubrie of Hebden Bridge in Yorkshire.

The introduction of extracts of Rauwolfia serpentina into western medical practice was marred by the observation that severe mental depression could appear in patients treated with the drug. Such reports first appeared in the mid-1950s. Reports of suicide while taking the drug led to increasing wariness in its use.

Clinical observations led to laboratory investigations throwing light on the basic biochemical mechanisms of depressive illness. In 1956 it was shown that reserpine could cause the level of 5 hydroxytryptamine $(5-\mathrm{HT})$ in the brain to fall (Pletscher et al., 1956). It seems that the enzyme which leads to the degradation of 5-hydroxytryptophan to 5-HT is also concerned with the decarboxylation of dopa to dopamine, a precursor of noradrenaline.

Since the Rauwolfia episode, numerous new drugs have been introduced into medical practice for the treatment of hypertension; one of these is methyldopa which inhibits decarboxylation of dopa in vitro (Sourkes, 1965) and in vivo (Oates et al., 1960), and can therefore be presumed to have an action analogous to reserpine.

Several of the early clinical assessments of methyldopa report an incidence of depression in patients on the drug of around 4-6\% (Hamilton, 1968; Johnson et al., 1966). There is some impression that patients manifesting such depression have a previous history of the disorder and to date it has not been established that the emotional disorder is a true side effect of methyldopa.

Careful assessment by experienced psychiatrists of populations under treatment with hypotensive drugs do not appear to have been carried out, possibly because of the many difficulties entailed in mounting such an exercise. Yet more knowledge in this area is required.

The recent development of self-rating scales for psychiatric disorder has added a useful dimension to epidemiological investigations, but their use calls for caution, and it is hoped that our experience will highlight some of the precautions that should be taken in their use.

McCoubrie and I planned to estimate the prevalence of mental illness in patients taking drugs for hypertension. Individual psychiatric examination, even of small numbers, being impracticable with our resources, we chose to survey a large population by the self-rating method. A recently validated rating scale, the Wakefield self-assessment of depression inventory (Snaith et al., 1971) was selected for the purpose.

In spite of its appellation, this inventory is not a diagnostic instrument; nor, when examined critically, is any self-rating scale. The Wakefield inventory requires the patient to record the degree to which he presently suffers from each one of 12 symptoms. Some of these symptoms reflect anxiety rather than depression, but symptoms of anxiety are common in depressive illness and this is recognized in the Hamilton depression rating scale.

In a population of patients diagnosed as suffering from endogenous depression the correlation of Wakefield with Hamilton scores was 0.87 . Before this inventory could be used with any confidence in our research, a further validation procedure was necessary to determine whether the inventory could be used with confidence to detect those suffering from less defined states of anxiety and depression in a general practice setting. Five general practitioners took part in this validation study. The practitioners handed the inventories to patients for completion; before completion each patient was rated by his practitioner for mental illness on a five-point scale and for physical illness on a four-point scale. 135 inventories were returned of which three were invalid owing to inadequate use.

Of the remaining 132 the correlation between the inventory scores and the practitioners' ratings for mental illness was 0.57. There was a positive correlation between scores and physical illness ratings of 0.32 . The partial correlation between the Wakefield inventory scores and mental illness with the effect of 
physical illness excluded was 0.54 . This correlation is significant beyond the one in a thousand level and it was considered that the use of the Wakefield inventory could be justified as an instrument for the detection of mental illness in the present research.

In this investigation the inventory was handed to all patients undergoing drug treatment for hypertension and its complications in a large group practice. As in the validation study the degree of physical incapacity of each patient was rated on the four-point scale in addition to the age, sex and drug, or combination of drugs, currently taken.

The inventory scores of those judged to be mentally healthy (recorded by the practitioners as having 0 or 1 ratings) from the validation study, were used as a comparison group. A preliminary statistical analysis was undertaken and the results are shown in Table 1.

Only patients on frusemide showed significantly raised Wakefield scores. The reason for this unexpected finding was soon detected from inspection of the data; patients on frusemide were more likely to be rated as suffering from severer degrees of physical illness, and indeed the partners in the practice stated

Table 1

$\begin{array}{lrc} & & \begin{array}{c}\text { Wakefield } \\ \text { Group }\end{array} \\ \text { Comparison } & n & \text { means } \\ \text { Methyldopa } & 56 & 8.91 \\ \text { Reserpine } & 87 & 10.40 \\ \text { Bethanidine } & 8 & 12.00 \\ \text { Chlorthalidone } & 12 & 9.67 \\ \text { Thiazides } & 14 & 6.64 \\ \text { Frusemide } & 35 & 10.34 \\ \text { Theobrom. + phenobarbitone } & 2.6 & 12.46^{*} \\ & 11 & 12.64 \\ \text { * F=5.34; } P<0.05 . \chi^{2}=4.36 ; P<0.05 . & \end{array}$

\section{References}

HAMILTON, M. (1968). Some aspects of the treatment of severe hypertension with methyldopa. Postgrad. Med.J., 44, 66-69.

JOHNSON, O., KITCHIN, A.H., LOWTHER, C.P. \& TUMER, R.W.D. (1966). Treatment of hypertension with methyldopa. Brit. med.J., 1, 133-137.

OATES, J.A., SELIGMANN, A.W., CLARK, M.A., ROUSSEAU, P. \& LEE, R.E. (1965). The relative efficacy of guanethidine, methyldopa and pargyline and antihypertensive agents. New Engl. J. Med., 273, 729-734. that they had a preference for the use of this drug when cardiac failure complicated hypertension.

Not only physical illness, but age and sex have some influence upon inventory scores. In order to determine the effect of drugs alone on the inventory scores, it was therefore necessary to discount the effect of these three variables; this was done by a computer programme using a method of partcorrelation. The resulting correlations of each drug with the Wakefield score are shown in Table 2.

None of these correlations is significant and it is, therefore, practically certain that the preliminary finding of significantly higher scores in patients on frusemide was due to more severe degrees of physical illness in patients on this drug.

This study, we think, illustrates not only the use, but some of the pitfalls of self-rating scales in epidemiological research.

Self-rating scales are not diagnostic instruments: even in the most carefully constructed of them, scores are subject to a variety of influences beside that of the disease itself. Used with caution they have a place in screening procedures of large populations.

Table 2

$\begin{array}{lr}\text { Methyldopa }>1 \mathrm{~g} / \text { day } & 0.005 \\ \text { Methyldopa }<1 \mathrm{~g} / \text { day } & 0.048 \\ \text { Bethanidine } & -0.007 \\ \text { Guanethidine } & -0.036 \\ \text { Reserpine } & 0.020 \\ \text { Theobrom. + Phenobarbitone } & 0.057 \\ \text { Thiazide diuretics } & 0.049 \\ \text { Thiazide diuretics + potassium } & 0.017 \\ \text { Chlorthalidone } & -0.080 \\ \text { Hydrochlo. + Amil. } & 0.043 \\ \text { Frusemide } & 0.057\end{array}$

PLETSCHER, A., SHORE, P.A., BRODIE, B.B. (1956). Serotonin as a mediator of reserpine action in the brain. J. Pharmac., 116, 84-89.

SNAITH, R.P., AHMED, S.N., MEHTA, S. \& HAMILTON, M. (1971). The assessment of the severity of primary depressive illness. Wakefield Self-Assessment Depression Inventory. Psychol. Med., 1, 143.

SOURKES, T.L. (1965). Action of methyldopa in the brain. Br. med. Bull., 21, 66-69. 